\title{
Evaluation of autonomic nervous system in children with spastic cerebral palsy: clinical and electophysiological study
}

\author{
Hanan G. Azouz' , Ali M. AbdelMohsen ${ }^{1}$, Hayam M. Abdel Ghany ${ }^{2^{*}}$ (i) and Rana M. Mohamed
}

\begin{abstract}
Background: Cerebral palsy (CP) is the most prevalent severe motor disability among children. The aim of this work was to assess autonomic dysfunction in children with cerebral palsy clinically and electrophysiologically.

Results: Age of the studied children ranged from 4 to 12 years. Quadriplegic type of spastic cerebral palsy constituted $82.5 \%$ of CP children while diplegic type constituted 17.5\%. Based on Gross Motor Function Classification System (GMFCS), the majority of children were in levels 4 and 5. The prevalence of autonomic dysfunction symptoms were $80 \%$ for thermoregulatory abnormalities (cold extremities), 65\% for chronic constipation, $52.5 \%$ for sleep disturbance, $47.5 \%$ for loss of appetite, $40 \%$ for sweating abnormalities, $25 \%$ for recurrent nausea and/or vomiting, $22.5 \%$ for increased sensitivity to light or dark and 15\% for bloating. As regards sympathetic skin response, 19 CP children had unobtainable response in both upper and lower limbs while 5 children had unobtainable response in lower limbs only. All of them were in levels 4 and 5 of GMFCS. Postural hypotension was present in 20\% of CP children. Mean Heart rate of $C P$ children was significantly increased more than healthy children upon head tilt test.
\end{abstract}

Conclusions: Autonomic dysfunction has been objectively proven in CP children through absent sympathetic skin response, presence of orthostatic tachycardia and postural hypotension.

Keywords: Cerebral palsy, Sympathetic skin response, Heart rate, Gross motor function classification system

\section{Background}

Cerebral palsy $(\mathrm{CP})$ is the commonest cause of motor disability in childhood [1,2]. It has been described as a group of disorders of the development of movement and posture causing activity limitations that are attributed to non-progressive disturbances that occurred in the developing fetal or infant brain [3]

The autonomic nervous system (ANS) is made up of pathways of neurons that control various organ systems inside the body through chemicals and signals to maintain homeostasis. It consists of the sympathetic and parasympathetic systems. The sympathetic component

\footnotetext{
*Correspondence: hayam_mstf@yahoo.com

2 Physical Medicine, Rheumatology and Rehabilitation Department,

Faculty of Medicine, Alexandria University, Alexandria 21321, Egypt

Full list of author information is available at the end of the article
}

is known as "fight or flight" and the parasympathetic component as "rest and digest." It functions without conscious control throughout the lifespan of an organism to control cardiac muscle, smooth muscle, and exocrine and endocrine glands. This, in turn, regulates blood pressure, urination, bowel movements, and thermoregulation [4]. Despite autonomic dysfunction being very common and severely affecting the quality of life of CP children, there has been virtually few research in this area. So, the aim of this work was to assess autonomic dysfunction in children with cerebral palsy clinically and electro-physiologically and to relate the results to the level of motor impairment as classified by the Gross Motor Function Classification System. 


\section{Methods}

The study was carried out on sixty children divided into two groups:

Group I: Forty children with spastic cerebral palsy. They were randomly selected from those attending the outpatient Neurology Clinic and Physical Medicine, Rheumatology and Rehabilitation Clinic.

Group II: Twenty healthy children of matched age and sex serving as a control group for sympathetic skin response and Heart rate variability.

We excluded children with any cardiac pathology which may affect heart rate. Children having any disease that has an effect on the peripheral nervous system as diabetes were excluded through history taking and peripheral sensory and motor conduction study. Also, children taking medication known to influence autonomic nervous system as $\beta$ blocker and antiepileptic drugs were excluded.

The study was explained to the participants and their parents and a written consent was taken from parents of all children included in the study.

Group I was subjected to the following:

1- Thorough history taking consisting history of any symptoms of autonomic dysfunction [5] through questionnaire directed to the parents consisting of 8 items: thermoregulatory (2 items): cold extremities and sweating abnormalities. gastro-intestinal (4 items): loss of appetite, bloating, chronic constipation, and recurrent nausea and/or vomiting $(\mathrm{N} \& / \mathrm{V})$, pupillo-motor (1 item): increased sensitivity to light and sleep disturbances (1 item).

2- Blood pressure was measured in supine position and $90^{\circ}$ head up position either by standing or passively holding the child in upright position to assess presence of postural hypotension [6]. Postural hypotension: reduction of systolic blood pressure at least 20 $\mathrm{mmHg}$ or diastolic pressure $10 \mathrm{mmHg}$ within $3 \mathrm{~min}$ of standing or passive head up tilt $[6,7]$.

3- Complete neurological examination was done including the following [8]:

- Mental state, posture, cranial nerves examination, motor system examination; muscle strength, tone, bulk and reflexes, and sensory system examination.

4- Assessment of function by Gross Motor Function Classification System (GMFCS) [9]

Both groups were subjected to the following:
I. Electrophysiological study to assess sympathetic skin response (SSR) $[10,11]$

II. Cardiac electrocardiogram test to assess heart rate variability (HRV) [12]

\section{Sympathetic skin response $[10,11]$}

Stimulation parameters: electric stimulation used. Frequency $0.1 \mathrm{HZ}$, sharp square impulse of $0.2 \mathrm{~ms}$ duration with current intensity of 10-30 mA. Vertical gain ranged from 5 to $100 \mathrm{uV} /$ division and analysis time was $5 \mathrm{~s}$ for the upper limb and $10 \mathrm{~s}$ for the lower limb. Filter setting: low cut $20 \mathrm{HZ}$, high cut $3 \mathrm{kHz}$. Room temperature was adjusted at $25^{\circ} \mathrm{C}$.

With repetitive stimulation, the inter-stimulus interval should not be more frequent than $1 /$ min to minimize the phenomenon of habituation.

\section{Sympathetic skin response of the upper limb}

The stimulating electrode was placed on the median nerve at the wrist, cathode was directed distally, and the nerve was stimulated on the same side of recording. The recording electrodes were placed so the active electrode was put on the palmar aspect of the hand and the reference electrode was put on the dorsum of the hand. The ground electrode was placed at the wrist region (Fig. 1).

\section{Sympathetic skin response of the lower limb}

The stimulating electrode was placed on the posterior tibial nerve above and posterior to the medial malleolus, cathode was directed distally, and the nerve was stimulated on the same side of recording. The recording electrodes were placed so the active electrode was put on the plantar aspect of the foot and the reference electrode was put on the dorsum of the foot. The ground electrode was placed at the ankle region (Fig. 2).

The following parameters were assessed for sympathetic skin response [13]

1-Onset latency in seconds (s): measured from stimulus artifact to the first deflection from base line.

2-Amplitude in microvolt $(\mu \mathrm{V})$ : measured from the peak of the first deflection to the peak of the next one (peak to peak)

At least three trials were carried out before we considered the response to be unobtainable. For diagnosis of autonomic neuropathy by sympathetic skin response, we consider abnormal SSR if there is absence of SSR [14].

\section{Heart rate variability [12]}

- Heart rate variability through 12 lead ECG with long strip lead II in both supine and in $90^{\circ}$ head up posi- 


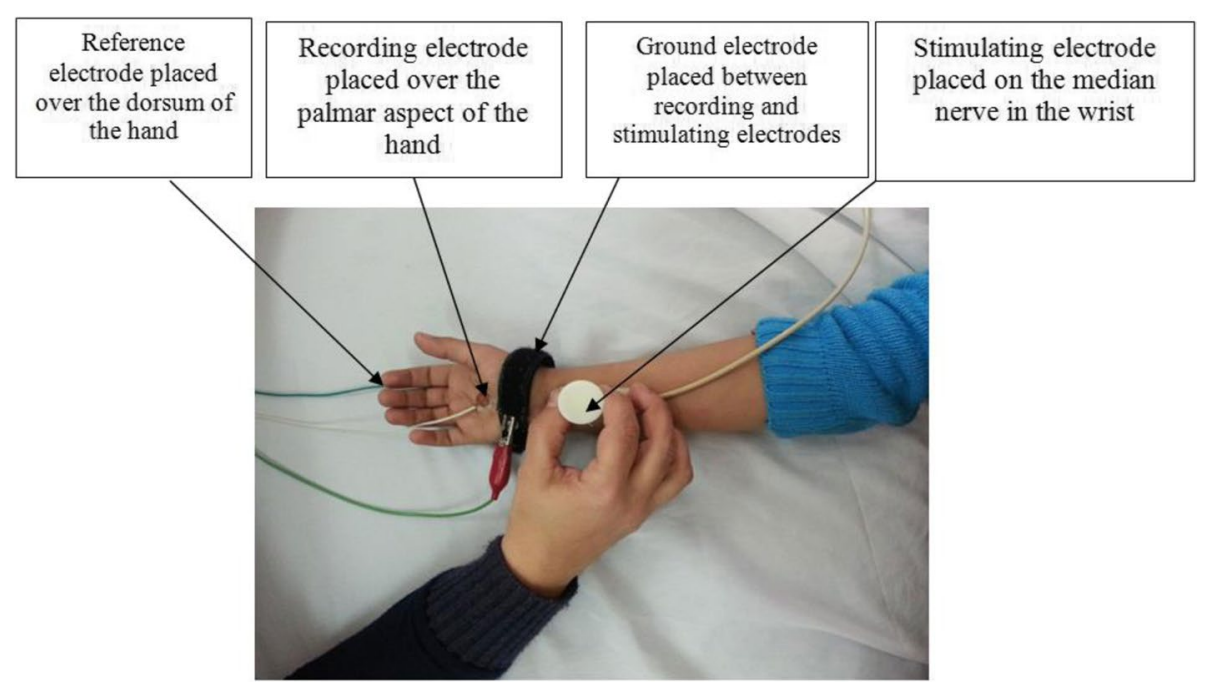

Fig. 1 Sympathetic skin response recording of the upper limb

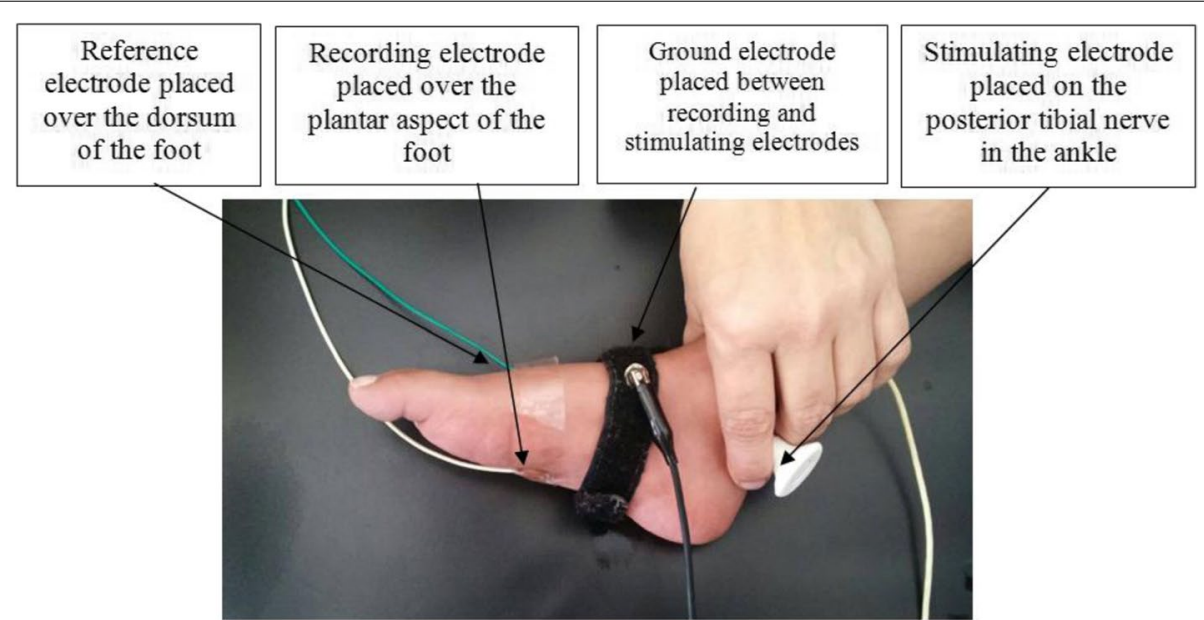

Fig. 2 Sympathetic skin response recording of the lower limb

tions after 10 min of active standing or passively by holding the child in upright position.

- Each QRS complex in long lead II strip was detected and the so-called R-R intervals (RRI) (that is all intervals between adjacent QRS complexes resulting from sinus node depolarization) were calculated.

- Time domain measures that were calculated included the mean R-R interval and the mean heart rate.

Orthostatic tachycardia: in pediatric age is defined as a rise in heart rate for at least 40 beats/min or heart rate more than 130 beats/min within $10 \mathrm{~min}$ of active standing or passive head-up tilt $[6,15]$.
Postural orthostatic tachycardia syndrome (POTS) is characterized by orthostatic tachycardia without orthostatic hypotension and may be accompanied by symptoms of orthostatic intolerance [6].

\section{Statistical analysis of the data [16]}

Data were fed to the computer and analyzed using IBM SPSS software package version 20.0. (Armonk, NY: IBM Corp.) Qualitative data were described using number and percent. The Kolmogorov-Smirnov test was used to verify the normality of distribution. Quantitative data were described using range (minimum and maximum), 
mean, standard deviation, and median. Significance of the obtained results was judged at the $5 \%$ level.

\section{Results}

In the current study, males constituted $60 \%$, while females constituted $40 \%$ of the total number of both CP children and healthy children. The mean age of CP children was $7.76 \pm 2.82$ years (ranged from 4 years to 12 years) with no statistical difference between CP children and healthy children regarding age.

The quadriplegic children constitute $82.5 \%$ of the studied CP while the diplegic children constitute $17.5 \%$. Based on GMFCS, most of CP children were in levels 4 $(45 \%)$ and $5(37.5 \%)$. Only $12.5 \%$ of children were in level 2 and $5 \%$ were in level 3 .

The most encountered symptom of autonomic dysfunction was cold extremities. It was present in $80 \%$ of the CP children, followed by chronic constipation in $65 \%$, sleep disturbances in $52.5 \%$, loss of appetite in $47.5 \%$, sweating abnormalities in $40 \%$, recurrent nausea and/or vomiting $(\mathrm{N} \& / \mathrm{V})$ in $25 \%$, and increased sensitivity to light in $22.5 \%$. The least encountered symptom was bloating in $15 \%$. Motor and sensory conduction studies were normal in the examined children. According to the response to SSR of the CP children, we recorded 19 CP children with unobtainable SSR in the upper and lower limbs and five children with unobtainable SSR in the lower limbs (LL) only. Consequently the total number of unobtainable SSR in the LLs was 24. So we considered the number of children with unobtainable SSR LLs more appropriate as a representative of the total number of children with unobtainable SSR (Fig. 3).

Regarding the results of obtainable SSR among CP children, the mean latency of the upper limbs (UL) was 1.11 $\pm 0.23 \mathrm{~s}$ and the mean amplitude was $64.44 \pm 27.07 \mu \mathrm{V}$. The mean latency of the lower limbs was $1.51 \pm 0.45 \mathrm{~s}$, and the mean amplitude was $62.53 \pm 23.59 \mu \mathrm{V}$. There was no significant difference between obtainable SSR among $\mathrm{CP}$ children and healthy children.
All autonomic dysfunction symptoms were more common in children with unobtainable SSR than children with obtainable SSR with statistical significances as regards cold extremities, chronic constipation, sleep disturbances, and sweating abnormalities (Table 1).

The mean heart rate (HR) of $\mathrm{CP}$ children in supine position was $100.83 \pm 15.28$ beats/min with mean $\mathrm{R}-\mathrm{R}$ interval (RRI) $0.60 \pm 0.10 \mathrm{~s}$, and the mean $\mathrm{HR}$ in $90^{\circ}$ head up position was $115.18 \pm 19.77$ beats/min with mean RRI $0.54 \pm 0.10 \mathrm{~s}$. The mean heart rate of healthy children in supine position was $98.15 \pm 8.93$ beats $/$ min with mean RRI $0.61 \pm 0.06 \mathrm{~s}$, and the mean HR in $90^{\circ}$ head up position was $103.80 \pm 8.58$ beats/min with mean RRI $0.58 \pm$ $0.06 \mathrm{~s}$. There was significant difference between HR and RRI between the two positions in the two groups, $P<$ 0.001in both groups.

As regards heart rate variability (HRV), there was no significant difference between two groups regarding supine mean HR and mean RRI but there was significant difference between two groups regarding mean HR and mean RRI in $90^{\circ}$ head up position (Table 2).

Orthostatic tachycardia was present in $35 \%$ of CP children. Of them, $20 \%$ had orthostatic tachycardia with postural hypotension while, $15 \%$ of them without postural hypotension (Figs. 4 and 5).

ALL CP children with orthostatic tachycardia had unobtainable SSR except 2 had obtainable SSR.

All the children with unobtainable SSR were in levels 4 and 5. No children in levels 2 or 3 had unobtainable SSR.

Regarding the relation between orthostatic tachycardia and GMFCS, only one affected child was in GMFCS level 2 and the rest of affected children were in levels 4 and 5 (Table 3).

\section{Discussion}

The autonomic nervous system (ANS) can be divided into the sympathetic and the parasympathetic nervous systems. To shed more light on the involvement of the

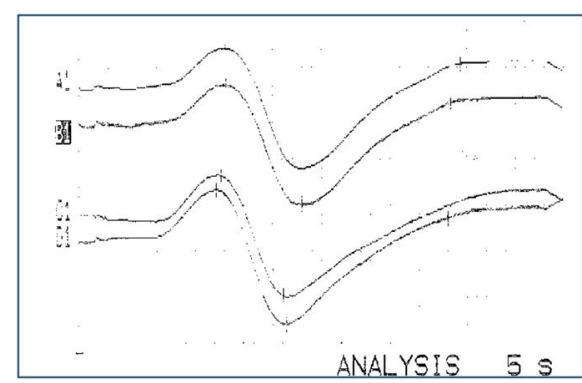

(A)

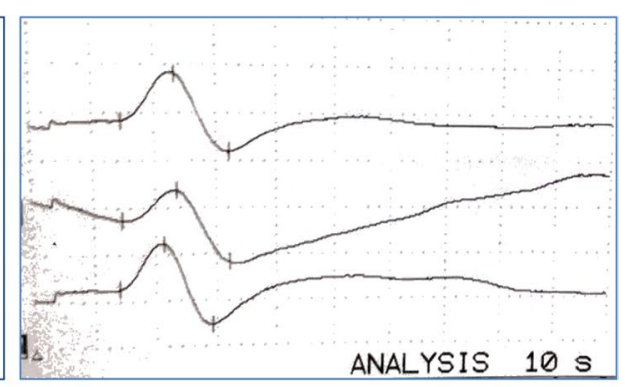

(B)

Fig. 3 A Normal sympathetic skin response upper limb. B Normal sympathetic skin response lower limb 
Table 1 Relation between SSR lower limbs with autonomic dysfunction symptoms sympathetic skin response (SSR)

\begin{tabular}{|c|c|c|c|c|c|c|}
\hline \multirow[t]{3}{*}{ Autonomic dysfunction symptoms } & \multicolumn{4}{|c|}{ SSR lower limbs } & \multirow[t]{3}{*}{$x^{2}$} & \multirow[t]{3}{*}{$P$} \\
\hline & \multicolumn{2}{|c|}{ Unobtainable $(n=24)$} & \multicolumn{2}{|c|}{ Obtainable $(n=16)$} & & \\
\hline & No. & $\%$ & No. & $\%$ & & \\
\hline Cold extremities & 22 & 91.7 & 10 & 62.5 & $5.104^{*}$ & ${ }^{\mathrm{FE}} P=0.042^{*}$ \\
\hline \multicolumn{7}{|l|}{ Sweating abnormalities } \\
\hline Increased (hyperhidrosis) & 4 & 40.0 & 6 & 100.0 & $5.760^{*}$ & ${ }^{\mathrm{FE}} P=0.034^{*}$ \\
\hline Decreased (hypohidrosis) & 6 & 60.0 & 0 & 0.0 & & \\
\hline Loss of appetite & 13 & 54.2 & 6 & 37.5 & 1.069 & 0.301 \\
\hline Bloating & 5 & 20.8 & 1 & 6.3 & 1.601 & ${ }^{\mathrm{FE}} P=0.373$ \\
\hline Chronic constipation & 20 & 83.3 & 6 & 37.5 & $8.864^{*}$ & $0.003^{*}$ \\
\hline Recurrent nausea and/or vomiting & 8 & 33.3 & 2 & 12.5 & 2.222 & ${ }^{\mathrm{FE}} P=0.263$ \\
\hline Increased sensitivity to light & 6 & 25.0 & 3 & 18.8 & 0.215 & ${ }^{\mathrm{FE}} P=0.717$ \\
\hline Sleep disturbances & 17 & 70.8 & 4 & 25.0 & $8.087^{*}$ & $0.004^{*}$ \\
\hline
\end{tabular}

$X 2$ chi-square test, FE Fisher's exact test

*Statistically significant at $P \leq 0.05$

Table 2 Comparison between the two studied groups according to HRV

\begin{tabular}{|c|c|c|c|c|c|}
\hline & HRV & $\begin{array}{l}\text { Cerebral palsy children }(n \\
=40)\end{array}$ & Healthy children $(n=20)$ & $t$ & $P$ \\
\hline \multirow[t]{8}{*}{ Supine } & Mean HR(beat/min) & & & & \\
\hline & Min.-max. & 76.0-136.0 & 78.0-107.0 & 0.854 & 0.397 \\
\hline & Mean $\pm S D$ & $100.83 \pm 15.28$ & $98.15 \pm 8.93$ & & \\
\hline & Median & 103.0 & 101.50 & & \\
\hline & Mean RRI (s) & & & & \\
\hline & Min.-max. & $0.44-0.78$ & $0.56-0.76$ & 0.448 & 0.656 \\
\hline & Mean \pm SD & $0.60 \pm 0.10$ & $0.61 \pm 0.06$ & & \\
\hline & Median & 0.58 & 0.59 & & \\
\hline \multirow[t]{8}{*}{$90^{\circ}$ head up } & Mean HR(beat/min) & & & & \\
\hline & Min.--max & $76.0-166.0$ & $80.0-111.0$ & $3.102^{*}$ & $0.003^{*}$ \\
\hline & Mean \pm SD & $115.18 \pm 19.77$ & $103.80 \pm 8.58$ & & \\
\hline & Median & 118.0 & 107.0 & & \\
\hline & Mean RRI (s) & & & & \\
\hline & Min.-max & $0.36-0.79$ & $0.53-0.74$ & $2.018^{*}$ & $0.048^{*}$ \\
\hline & Mean \pm SD & $0.54 \pm 0.10$ & $0.58 \pm 0.06$ & & \\
\hline & Median & 0.51 & 0.56 & & \\
\hline
\end{tabular}

$P P$ value for comparing between the two groups, $H R V$ heart rate variability, $R R I R-R$ interval, $H R$ heart rate

$t$ Student's $t$ test

*Statistically significant at $P \leq 0.05$

ANS in children with CP, the SSR and HRV tests were used in this study. SSR and HRV analyses are non-invasive and easily applicable electrophysiological tests.

Most of our patients were in grades 4 and 5 GMFCS this is explained by the high prevalence of quadriplegic type-the most severe type of cerebral palsy-among the studied group ( $82.5 \%$ ) as our hospital is a tertiary center so severe cases were referred to it.
Two different evaluation attitude of SSR have been presented. Either the qualitative evaluation with the absence of SSR as a pathological sign or the quantitative evaluation by comparing latency and amplitude [17]. In the current study, we depended on the absence or presence of SSR to assess the autonomic dysfunction as there is no significant difference between children with obtainable SSR and the control group. 
(A)

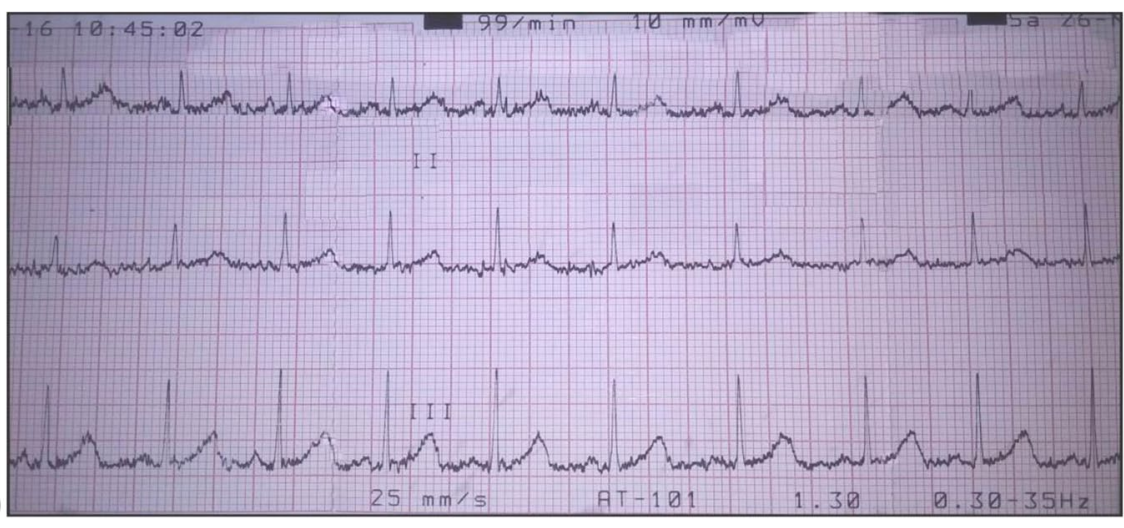

(B)

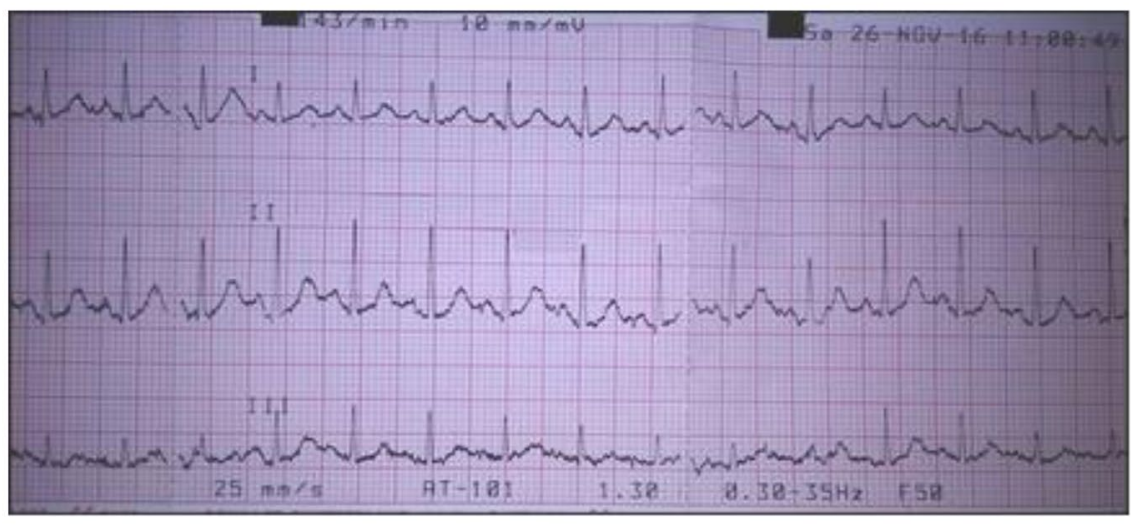

Fig. 4 Abnormal response to orthostatic stress (orthostatic tachycardia). A Electrocardiogram in supine position with mean heart rate 103 beats/ min. B Electrocardiogram in $90^{\circ}$ head up position with mean heart rate 146 beats $/$ min

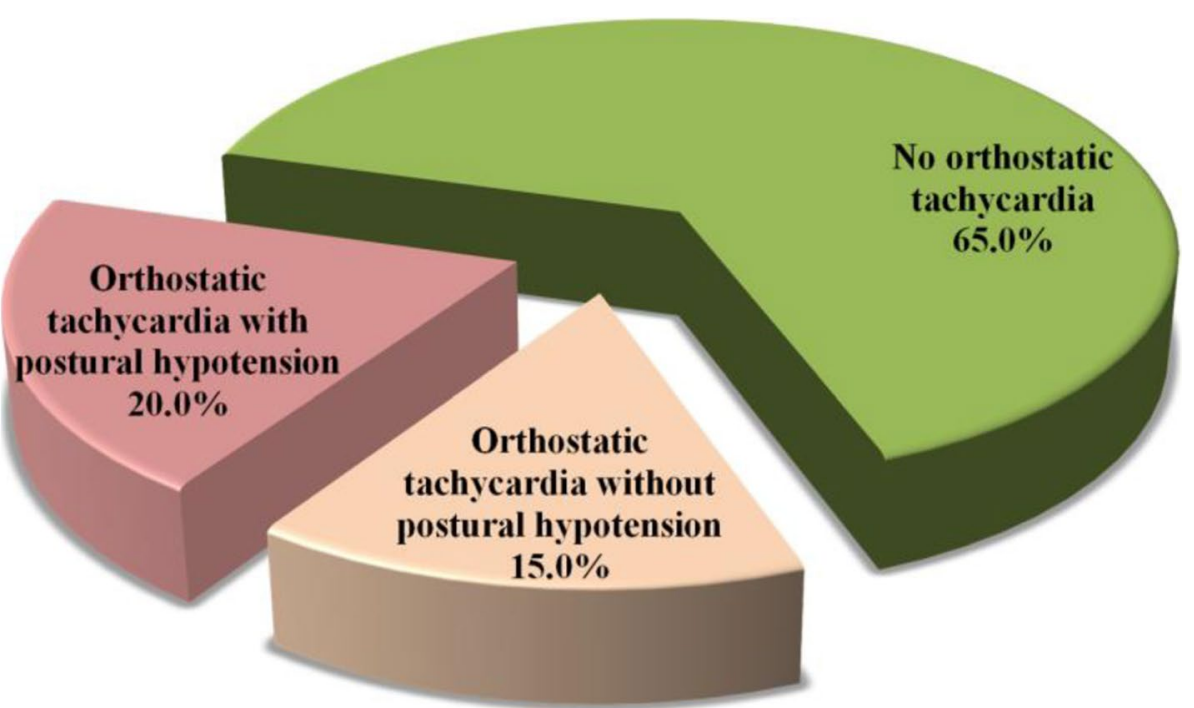

Fig. 5 Distribution of the cerebral palsy children according to presence of orthostatic tachycardia and postural hypotension $(n=40)$ 
Table 3 Relation between GMFCS with SSR and orthostatic tachycardia

\begin{tabular}{|c|c|c|c|c|c|c|c|c|c|c|}
\hline \multirow[t]{3}{*}{ SSR } & \multicolumn{8}{|c|}{ GMFCS } & \multirow[t]{3}{*}{$x^{2}$} & \multirow[t]{3}{*}{${ }^{M C_{p}}$} \\
\hline & \multicolumn{2}{|c|}{$2(n=5)$} & \multicolumn{2}{|c|}{$3(n=2)$} & \multicolumn{2}{|c|}{$4(n=18)$} & \multicolumn{2}{|c|}{$5(n=15)$} & & \\
\hline & No. & $\%$ & No. & $\%$ & No. & $\%$ & No. & $\%$ & & \\
\hline \multicolumn{11}{|l|}{ UL } \\
\hline Unobtainable & 0 & 0.0 & 0 & 0.0 & 11 & 61.1 & 8 & 53.3 & $7.367^{*}$ & $0.035^{*}$ \\
\hline Obtainable & 5 & 100.0 & 2 & 100.0 & 7 & 38.9 & 7 & 46.7 & & \\
\hline \multicolumn{11}{|l|}{ LL } \\
\hline Unobtainable & 0 & 0.0 & 0 & 0.0 & 13 & 72.2 & 11 & 73.3 & $11.734^{*}$ & $0.003^{*}$ \\
\hline Obtainable & 5 & 100.0 & 2 & 100.0 & 5 & 27.8 & 4 & 26.7 & & \\
\hline Orthostatic tachycardia & 1 & 20.0 & 0 & 0.0 & 8 & 44.4 & 5 & 33.3 & 1.845 & 0.673 \\
\hline
\end{tabular}

$X 2$ chi-square test, MC Monte Carlo, GMFCS Gross Motor Function Classification System, SSR sympathetic skin response, UL upper limb, LL lower limb (LL)

*Statistically significant at $P \leq 0.05$

To our knowledge, the relationship between sympathetic reflex activity and motor function capacity in patients with CP has not been fully investigated.

SSR was unobtainable in $19 \mathrm{CP}$ children in the upper and lower limbs and five children in the lower limbs (LL) only, all of them were in levels 4 and 5 of GMFCS. These results were in agreement with previous study done by Ogawa et al. [18] which revealed no sympathetic skin response in patients with severe motor and intellectual disabilities. However, all patients in their study with mild or moderate motor and intellectual disabilities showed sympathetic skin response.

On the other hand, Yang et al. [19] demonstrated no significant difference between their studied CP children and healthy controls regarding SSR. The authors did not enroll in their study children with severe quadriplegia in the contrary to current study where the majority of the studied children were quadriplegic in levels 4 and 5 of GMFCS.

All children with CP had normal peripheral conduction study, and absence of SSR in some children suggesting that the autonomic dysfunction is the result of central nervous system impairment.

The central localization of SSR is not well known. It is thought that the mesencephalic reticular formation and posterior hypothalamus play an important role in the formation of this reflex. The cerebral cortex plays an important role in the modification of the response. This arrangement is claimed to be made through the corticoreticular tracts [20]. It is thought that the cerebral cortex demonstrates its inhibitory and excitatory effects on the sudomotor sympathetic activity on the contralateral side of the body. But the exact mechanism and the localization of the effective cortical areas are not known [21]. Abnormalities of SSR in CP need more studies to investigate the pathogenesis of these abnormalities.

Children with unobtainable SSR had a significant relation to autonomic dysfunction than those with obtainable SSR. However, research were needed to detect if SSR can be used as an early predictor to autonomic dysfunction.

Postural hypotension was assessed through blood pressure examination in supine and $90^{\circ}$ head up position. Twenty percent of $\mathrm{CP}$ children had postural hypotension.

In healthy individuals, if the blood pressure falls upon standing, the baroreceptors which are located in the walls of the highly elastic great vessels, send fewer signals so parasympathetic activity decreases, allowing the heart rate to rise. More important, sympathetic neural impulse activity increases and causes stimulation of the rate and contractility of the heart, and constriction of arteriolar and venous blood vessels. These effects serve to reverse the drop of blood pressure [22].

In individuals having postural hypotension, it is ascribed to defective increase in arterial resistance and excessive venous pooling upon standing or passive head up position [23]. It may also be attributed to imbalance between sympathetic and parasympathetic systems [22].

Regarding HRV, CP children showed higher supine mean HR than healthy children but with no significant difference between them. This result was compatible with Ferriera et al. study [24], and Park et al. study [25], both studies demonstrated non-significant increase in resting mean $\mathrm{HR}$ in $\mathrm{CP}$ children than healthy children. Yet, it was inconsistent with Yang et al. study [19], which showed significant increase of resting HR in CP children than healthy children. It was measured in relaxing sitting position and they attributed their result to increased energy consumption in CP children even upon sitting. 
Both CP children group and control group showed significantly increased mean HR in $90^{\circ}$ head up position than supine position. This is in agreement with the previous studies $[25,26]$ which demonstrated significantly increased mean heart rate in CP children during orthostatic test. They suggest that $\mathrm{CP}$ children have some difficulty in adjusting their sympathovagal balance to this stimulus.

The present study also showed significant difference between $\mathrm{CP}$ children and control group regarding mean HR during head up position which reflects that mean HR of CP children was markedly increased more than healthy children upon head up position.

Normally, during standing or head up position, vasovagal withdrawal and sympathetic predominance occur resulting in increase of heart rate and contractility [22]; this explains increased mean HR in healthy children during orthostatic stress.

Excessive increase of heart rate in head up position had occurred in 35\% of CP children meeting the definition of orthostatic tachycardia which is, considered one of manifestations of autonomic dysfunction. Orthostatic tachycardia occurs due to failure of peripheral vasculature to vasoconstrict appropriately during upright position leading to excessive increase in heart rate and contractility to maintain blood pressure in relatively normal levels. This mechanism may not be fully compensatory in cases with both orthostatic tachycardia and postural hypotension [27].

Orthostatic tachycardia is found more among children with unobtainable SSR and GMFCS levels 4 and 5 suggesting that those with severe cerebral palsy are more prone to autonomic dysfunction.

Fifteen percent of CP children had orthostatic tachycardia not associated with postural hypotension. Postural orthostatic tachycardia syndrome (POTS) may be suggested in these children [6]. It is considered a milder form of dysautonomia, and it was explained by relatively intact sympathetic arteriolar function with selectively impaired sympathetic venomotor function [21].

\section{Conclusion}

Autonomic dysfunction has been objectively proven in $\mathrm{CP}$ children through absent sympathetic skin response, presence of orthostatic tachycardia, and postural hypotension.

The current study recommends the use of sympathetic skin response and heart rate variability in investigating autonomic dysfunction in $\mathrm{CP}$ children, as they were proven to be simple and non-invasive procedures.

\section{Limitation of the present work}

- It was inapplicable to assess all symptoms of autonomic dysfunction in $\mathrm{CP}$ children as most of children could not express themselves.

- The objective assessment of the clinical autonomic symptoms might provide a better analysis of the relationship with SSR and HRV results.

- It was better to assess HRV through frequency domain which can differentiate between sympathetic cardiovascular dysfunction and parasympathetic dysfunction and assess sympathovagal imbalance more appropriately but it was not available.

\section{Abbreviations}

ANS: Autonomic nervous system; CP: Cerebral palsy; GMFCS: Gross Motor Function Classification System; HR: Heart rate; HRV: Heart rate variability; LLs: Lower limbs; N\&N: Nausea and/ or vomiting; POTS: Postural orthostatic tachycardia syndrome; RRI: R-R intervals; SSR: Sympathetic skin response; ULS: Upper limbs.

\section{Acknowledgements \\ To all patients who participate in this work and their family.}

\section{Authors' contributions}

Study concept and design: HG, AM, and HM. Collection of the patients: RM. Neurological examination of the patients and assessment of function by Gross Motor Function Classification System: HG. Assessment of blood pressure and heart rate variability: AM. Assessment of symptoms of autonomic dysfunction and sympathetic skin response: $\mathrm{HM}$. Analysis and interpretation of data: $\mathrm{HG}$, $A M$, and HM. Drafting of the manuscript: $H M, R M, H G$, and $A M$. Critical revision of the manuscript for important intellectual content: HM and HG. All authors have read and approved the manuscript.

\section{Funding}

This research did not receive any specific grant from funding agencies in the public, commercial, or non-profit sectors.

\section{Availability of data and materials}

Patients were selected from those attending the outpatient clinics of Neurology and Physical Medicine, Rheumatology and Rehabilitation (Alexandria University Children's Hospital) at El Shatby. Twenty healthy children of matched age and sex as a control group for sympathetic skin response and heart rate variability.

\section{Declarations}

Ethics approval and consent to participate

The study was approved by the local ethics committee of the Faculty of Medicine, Alexandria University serial number 0105150. The study was explained to the participants and their parents and a written consent was taken from parents of all children included in the study.

\section{Consent for publication}

All parents of participant accepted publication of this research.

\section{Competing interests}

The authors declare that they have no competing interests.

\section{Author details}

${ }^{1}$ Pediatric Department, Faculty of Medicine, Alexandria University, Alexandria 21321, Egypt. ${ }^{2}$ Physical Medicine, Rheumatology and Rehabilitation 
Department, Faculty of Medicine, Alexandria University, Alexandria 21321, Egypt.

Received: 14 July 2021 Accepted: 13 October 2021

Published online: 09 December 2021

\section{References}

1. Cans CH, De-La-Cruz J, Mermet M (2008) Epidemiology of cerebral palsy. Pediatr Child Health 18:393-398. https://doi.org/10.1016/j.paed.2008.05. 015

2. Himmelmann K, Hagberg G, Beckung E, Hagberg B, Uvebrant P (2005) The changing panorama of cerebral palsy in Sweden. IX. Prevalence and origin in the birth-year period 1995-1998. ActaPaediatr 94(3):287-294. https://doi.org/10.1111/j.1651-2227.2005.tb03071.x

3. Novak I, Morgan C, Adde L, Blackman J, Dmiano D, Cioni G et al (2017) Early,accurate diagnosis and early intervention in cerebral palsy: advances in diagnosis and treatment. JAMA Pediatr 171(9):897-907. https://doi.org/ 10.1001/jamapediatrics.2017.1689

4. McCorry LK (2007) Physiology of the autonomic nervous system. Am J Pharm Educ 71(4):78. https://doi.org/10.5688/aj710478

5. Suarez GA, Opfer-Gehrking TL, Offord KP, Atkinson EJ, O'Brien PC, Low PA (1999) The autonomic symptom profile: a new instrument to assess autonomic symptoms. Neurology 52(3):523-528. https://doi.org/10.1212/ wnl.52.3.523

6. Freeman R, Wieling W, Axelrod FB, Benditt DG, Benarroch E, Biaggioni I et al (2011) Consensus statement on the definition of orthostatic hypotension, neurally mediated syncope and postural tachycardia syndrome. Clin Auton Res 21(2):69-72. https://doi.org/10.1007/s10286-011-0119-5

7. Shalem T, Goldman M, Breibart R, Baram W, Kozer E (2013) Orthostatic hypotension in children with acute febrile illness. J EmergMed 44(1):2327. https://doi.org/10.1016/j.jemermed.2012.02.045

8. Swaiman KF (2006) Clinical evaluation: neurological examination of older child. In: Swaiman KF, Ashwal S, Ferriero DM (eds) Pediatric neurology: principles and practice, 4th edn. Mosby Elsevier, Philadelphia, pp 17-36

9. Palisano R, Rosenbaum P, Walter S, Russell D, Wood E, Galuppi B (1997) Development and reliability of a system to classify gross motor function in children with cerebral palsy. Dev Med Child Neurol 39(4):214-223. https://doi.org/10.1111/j.1469-8749.1997.tb07414.x

10. Dettmers C, Faust H, Fatepour D, Tackmann W (1993) Sympathetic skin response-physiologic principles, normal values and clinical use. Fortschr Neurol Psychiatr 61(11):369-377. https://doi.org/10.1055/s-2007-999107

11. Gutrecht JA (1994) Sympathetic skin response. J Clin Neurophysiol 11(5):519-524. https://doi.org/10.1097/00004691-199409000-00006

12. European Society of Cardiology and the North American Society of Pacing and Electrophysiology (1996) Heart rate variability. Standards of measurement, physiological interpretation, and clinical use. Task force of the European Society of Cardiology and the north American Society of Pacing and Electrophysiology. Eur Heart J 17(3):354-381

13. Elie B, Guiheneuc $P$ (1990) Sympathetic skin response: normal results in different experimental conditions. Electroencephalogr ClinNeurophysiol 76(3):258-267. https://doi.org/10.1016/0013-4694(90)90020-k
14. Vetrugno R, Liguori R, Cortelli P, Montagna P (2003) Sympathetic skin response. ClinAuton Res 13(4):256-270. https://doi.org/10.1007/ s10286-003-0107-5

15. Singer W, Sletten D, Low P, Fischer P, Brands C, Opfer-Gehrking T (2012) Postural tachycardia in children and adolescents what is abnormal? J Pediatr 160(2):222-226. https://doi.org/10.1016/j.jpeds.2011.08.054

16. Kirkpatrick LA, Feeney BC (2013) Asimple guide to IBM SPSS statistics for version 20.0 student. Cengage Learning, Wadsworth

17. Kucera P, Goldenberg Z, Kurca E (2004) Sympathetic skin response: review of the methods and its clinical use. Bratisl LekListy 105(3):108-116

18. Ogawa A, Hamamoto K, Hirose S, Fujikawa M, Mitsudome A (2007) Sympathetic skin response in patients with severe motor and intellectual disabilities. No To Hattatsu 39(5):347-350

19. Yang T, Chan R, Liao S, Chuang T, Liu T (1997) Electro-physiologic evaluation of autonomic function in cerebral palsy. Am J Phys Med Rehabil 76(6):458-461. https://doi.org/10.1097/00002060-199711000-00005

20. Korpelainen JT, Tolonen U, Sotaniemi KA, Myllyla WV (1993) Suppressed sympathetic skin response in brain infarction. Stroke 24:1389-1392. https://doi.org/10.1161/01.str.24.9.1389

21. Barin S, Murat E, Murat I, Aydan K, Müfit A (2006) Sympathetic skin responses in hemiplegic patients with and without complex regional pain syndrome. Neurol India 54(3):279-282

22. Reichgott M (1990) Clinical evidence of dysautonomia. In: Walker HK, Wall WD, Hurst JW (eds) Clinical methods: the history, the physical, and laboratory examinations, 3rd edn. Butterworths, Boston, pp 389-397

23. Smit AJ, Halliwill JR, Low PA, Wieling W (1999) Pathophysiological basis of orthostatic hypotension in autonomic failure. J Physiol 519:1-10. https:// doi.org/10.1111/j.1469-7793.1999.00010.x

24. Ferreira M, Pastore C, Imada R, Guare R, Leite M, Poyares D et al (2011) Autonomic nervous system in individuals with cerebral palsy: controlled study. J Oral Pathol Med 40(7):576-581. https://doi.org/10.1111/j.16000714.2011.01008.x

25. Park E, Cho S, Park C, Lee J, Kim J (2002) Assessment of autonomic nervous system with analysis of heart rate variability in children with spastic cerebral palsy. Yonsei Med J43(1):65-72. https://doi.org/10.3349/ymj. 2002.43.1.65

26. Jakub SG, Antonio RZ, Luiz Eduardo VS, Craig AW, Rafał B, Jerzy S et al (2020) Heart rate variability in children and adolescents with cerebral palsy — a systematic literature review. J Clin Med 9(4):1141. https://doi. org/10.3390/jcm9041141

27. Low P, Opfer-gehrking T, Textor S, Schondorf R, Suarez G, Fealey R et al (1994) Comparison of the postural tachycardia syndrome (POTS) with orthostatic hypotension duo to autonomic failure. J Auton Nerv Syst 50(2):181-188. https://doi.org/10.1016/0165-1838(94)90008-6

\section{Publisher's Note}

Springer Nature remains neutral with regard to jurisdictional claims in published maps and institutional affiliations.

\section{Submit your manuscript to a SpringerOpen ${ }^{\circ}$ journal and benefit from:}

- Convenient online submission

- Rigorous peer review

- Open access: articles freely available online

- High visibility within the field

Retaining the copyright to your article

Submit your next manuscript at springeropen.com 